\title{
Statistical Analysis of Rainfall Variability Effect on Wheat Production and Coping Strategies of Farmers: The Case of Agarfa District, Bale Zone, Ethiopia
}

\author{
Yilma Jambo $^{1 *} \quad$ Tadele Degefa ${ }^{2}$ \\ 1.Department of Rural Development and agricultural extension, Madda Walabu University, Robe, Ethiopia \\ 2.Department of Statistics, Madda Walabu University, Robe, Ethiopia
}

\begin{abstract}
This study aimed to assess the rainfall variability and its effect on wheat production in Agarfa district for the last sixteen years. Data on rainfall and crop yield for the period 2001-2016 was obtained from Agarfa meteorological station and District Agricultural Offices, respectively. Both qualitative and quantitative research design were used. Purposive sampling method was employed to select 256 respondents' from five kebeles for interview. The collected data was analyzed both qualitatively and quantitatively. Quantitative data was analyzed using mean, coefficient of variation, correlation and regression analysis to ascertain the relation, cause and effect relationship between rainfall characteristics and wheat yield. The trend analysis indicated that there was decreasing in rainfall by $4.5278 \mathrm{~mm}$ per year in the district over the last sixteen years. The productivity of winter wheat in the farm over the last sixteen years shows the trends of ups and downs which victimized by different climatic elements. The correlation coefficient indicated very strong positive relationship between productivity of wheat and annual rainfall. The regression model also depicts similar situation and corresponding p-value improved that the annual rainfall was the major determinants of wheat production in specified area. Hence, the investigator recommend that the district's agricultural center and any concerned body should give prior attention to minimize the risks of rainfall variability by using different mechanisms like reforestation, making local meteorology station at nearby, and developing coping strategies of farmers.
\end{abstract}

Keywords: Rainfall variability, wheat production, Agarfa district

DOI: $10.7176 / \mathrm{JBAH} / 11-4-02$

Publication date: February $28^{\text {th }} 2021$

\section{Background}

Current and predicted pattern of global climate change are a major concern in many areas of socio-economic activities, and is a threat for biodiversity and ecosystem function [1]. According to the IPCC [2], high level of greenhouse gas concentration in the atmosphere is the main cause of climate variability and global warming.

Due to global warming in the coming decades, the temperature is expected to increase between 2 and 5 degree Celsius [2]. This increase in temperature would cause melting of ice in the polar areas and potentially induce flooding in different parts of the world. In terms of rainfall, a study by Purkey et al. [3] indicated that in the coming century, the world will experience $40 \%$ to $100 \%$ more dry years compared to the past century. This indicates as crop water demand is expected to increase.

As a result of climate variability, a significant shift in the pattern of rainfall distribution is expected to occur in the coming decades [4]. These shifts in the amount and intensity of rainfall are also projected to affect agricultural productivity, land suitability and welfare levels of households which derive their livelihoods from agriculture [5]. Moreover, rainfall variability affects agriculture through reduced precipitation and increased evapotranspiration as an indirect result of a change in climatic variables other than the direct impacts on temperature and rainfall.

Ethiopian agriculture is mainly managed and operated by smallholder subsistence farmers. For instance, about $97 \%$ of crop production and $98 \%$ of the total area under crop cultivation is operated by private peasant holders, with average landholding size of 1.16 ha [6]. Agriculture is the major driver of economic growth especially in developing countries. Ethiopia is one of the least developing countries in which majority of its population depend on agriculture sector. Rising the agricultural production at the national level leads to improve overall economic growth and development. However, climate change has become a serious threat to sustainable economic growth [7].

Ethiopia is a poor country and its economy is highly depending on agriculture which had failed to meet the growing food demand. This is due to the fact that the negative effect of climate changes on agricultural production [8].

The other studies conducted in Bale zone of Sinana district by Bessie [8] indicated that the area has been highly vulnerable to extreme climatic events such as droughts; waterlog which resulted in significant yield reduction on major crops. Further studies reported by Bekele [10] revealed that kiremt rainfall total and length of growing period had moderate to strong positive correlation with cereal crops. This study, therefore attempted to 
evaluate wheat production and rainfall variability, identify trends on rainfall variability characteristics and farmers coping strategies of rainfall variability effects on wheat production in Agarfa district.

\section{MATERIALS AND METHODS}

Description of the study area

Agarfa is located in south east of Ethiopia at $460 \mathrm{~km}$ and $31 \mathrm{~km}$ from Addis Ababa and Zonal capital Robe respectively. Astronomically, the study district is located at Latitude of $7^{0} 21^{\prime} 12^{\prime}$ ' $\mathrm{N}$ and Longitude $39^{0} 54^{\prime} 22^{\prime}$ ' $\mathrm{E}$. The total area of the district is $1,343 \mathrm{~km}^{2}(134,300 \mathrm{ha})$ which ranked the $15^{\text {th }}$ largest districts among the zonal district. It accounts about 1.9 percent of the total areas of the zone. The mean Annual temperature of the district is $17.5^{\circ} \mathrm{c}$. The maximum and minimum temperatures are $25^{\circ} \mathrm{c}$ and $10^{\circ} \mathrm{c}$, respectively. The annual rainfalls are $800 \mathrm{~mm}$ whereas $1200 \mathrm{~mm}$ and $400 \mathrm{~mm}$ maximum and minimum annual rainfall recorded in the district.

\section{Research design}

For the successfulness of the study, cross sectional research design was used. Therefore data was collected from the household respondents to address the research objectives.

\section{Sampling techniques}

For this study the researchers was used multi-stage sampling procedure. First stage, 19 wheat produced kebele stratified into three Agro ecological zones those are Dega (four kebele), weina dega (eleven kebele) and kola (four kebele). In the second stage, out of those 19 kebeles five Kebeles such as (Galema Hebeno from dega), (Ali and Elabidu and kaso wara from weine dega) and Wabeseada from kola agro ecological zone were selected based on representativeness of different agro-ecologies. The main reason to choose those five kebeles was productivity and accessibility. Finally, from the total household of the study kebeles which were 3188, the sample household was computed by using Allyn and Bacon [11] sample size determination formula as follows.

$n=\frac{p q N}{(S E)^{2} N+p q}$

where $\mathrm{n}=$ sample size $\quad, \mathrm{SE}=$ standard error of the proportion, $\mathrm{p}=$ proportion of households engaged in farming, $\mathrm{q}=1-\mathrm{p}$ and, $\mathrm{N}=$ total household, $\mathrm{SE}=$ at $99 \%$ confidence level $=0.04, \mathrm{~N}=2470, \mathrm{p}=0.5, \mathrm{q}=1-0.5=0.5$

$n=\frac{0.5 \times 0.5 x(3188)}{(0.03)^{2} N+(0.25)}=256$

Accordingly, a total of 256 sample households were selected from the five sample kebeles by using simple random sampling.

\section{Data Collection Methods}

For this study both primary and secondary data were used. Primary data was collected from the sampled respondents using structured questionnaire that was pre tested before data collection. Secondary data was collected from different sources such as district agriculture office, research findings, internet and published and unpublished material which were relevant for this study.

\section{Methods of data analysis}

Analysis of socio-economic data

The study was employed both qualitative and quantitative data analysis techniques.

\section{Rainfall variability and wheat production trend analysis}

Several tests are available for the detection and estimation of trends. In this particular study, Mann-Kendall's test was employed. Mann-Kendall's test is a non-parametric method, which is less sensitive to outliers and test for a trend in a time series without specifying whether the trend is linear or non-linear [12]. The Mann-Kendall's test statistic is given as:

$$
S=\sum_{i=1}^{N-1} \sum_{j=i+1}^{N} \operatorname{sgn}\left(x_{j}-x_{i}\right),
$$

where $\mathrm{S}$ is the Mann-Kendal's test statistics; $\mathrm{x}_{\mathrm{i}}$ and $x_{j}$ are the sequential data values of the time series in the years $i$ and $j(j>i)$ and $\mathrm{N}$ is the length of the time series. A positive $S$ value indicates an increasing trend and a negative value indicates a decreasing trend in the data series. 


\section{The Sen's estimator of slope:}

This test is applied in cases where the trend is assumed to be linear, depicting the quantification of changes per unit time. This method could be used with missing data and remain unaffected by outliers or gross errors [13]. The slope (change per unit time) was estimated following the procedure of Sen [14].

Sen's slope estimator was computed as:

$$
T_{i}=\frac{x_{j}-x_{k}}{j-k} \text { for } i=1,2,3, \ldots, N,
$$

where $x_{j}$ and $x_{k}$ are considered as data value at time $k(j>k)$ correspondingly. The median of these $\mathrm{N}$ values of $T_{i}$ is represented as Sen's estimator of slope.

\section{Rainfall and wheat production Variability analysis}

Standardized anomaly index, precipitation concentration index and coefficient of variation were used as descriptors of rainfall variability with wheat production [15]. Standardized Anomaly Index (SAI) was calculated as the difference between the annual total of a particular year and the long term average rainfall records divided by the standard deviation of the long term data. This index is used to examine the nature of the trends and enables the determination of the dry and wet years in the record. Its formula is given as:

$$
z=\frac{x-\mu}{\delta}
$$

where, $\mathrm{x}$ is the seasonal total rainfall of a particular year; $\mu$ is mean of the observation and $\delta$ is the standard deviation of the observation. Based on $z$ values, drought severity classes are given as extreme drought $(z<$ $-1.65)$, severe drought $(-1.28>z>-1.65)$, moderate drought $(-0.84>Z>-1.28)$, and no drought $(z>-0.84)$ [16]. The same method was used by Ayalew et al. [17] to identify dry and wet years in their study. Precipitation Concentration Index (PCI) was analyzed using modified version of Oliver's [18]. It was computed as follows:

$$
P C I=\frac{\sum_{i=1}^{12} P_{i}^{2}}{\left(\sum_{i=1}^{12} P_{i}\right)^{2}} x 100
$$

Where, $P_{i}$ is the rainfall amount of the $i^{t h}$ month. PCI values below 10 indicate uniform monthly rainfall distribution; values between 11 and 20 indicate high concentrations of monthly rainfall distribution; and values of 21 and above indicate very high concentration of monthly rainfall distribution.

Coefficient of variation (CV) was calculated to evaluate crop yield with rainfall variability and its characteristics by dividing the standard deviation of the event to its mean.

Where CV can be computed as:

$$
C V=\left(\frac{S D}{\bar{x}}\right) * 100,
$$

where, $\mathrm{x}$ and $\delta$ are the average and standard deviation of rainfall, respectively over the given period. According to Hare [19], CV (\%) values are classified as follows: $<20 \%$ as less variable, $20-30 \%$ as moderately variable, and $>30 \%$ as highly variable.

On the other hand, standard deviation is computed as the square root of variance. Using the classification of Reddy [20], the stability of rainfall is examined as follows: when standard deviation $<10$ as very high stability, 1020 as high stability, and $20-40$ as moderate stability and $>40$ as less stability. Where SD can be computed as:

$$
S D=\sqrt{\sum_{i=1}^{n} \frac{\left(x_{i}-\bar{x}\right)^{2}}{n}}
$$

The Pearson's correlation coefficient was used to measure the strength of the association between wheat yield and rainfall variability. This produced a linear association. The range of correlation coefficients is ' 1 to +1 . The complete dependency between two variables is expressed by either ' 1 or +1 , and 0 represents the complete independency of the variables.

$$
r=\frac{\Sigma(x-\bar{x})(y-\bar{y})}{\sqrt{\sum(x-\bar{x})^{2}(y-\bar{y})^{2}}}
$$

The calculation of the correlation coefficient is performed in which $x$ represents the independent variable and $\mathrm{y}$ represents the dependent variable.

\section{Implementation of regression based models}

Regression models are statistical process for estimating the relationships among variables. They are based on the least square solution aiming at minimizing root mean square error (RMSE), and are normally presented in the following general form: 
$y_{i}=\alpha+\sum_{i=1}^{n} \beta_{i} x_{i}+\varepsilon$,

where: $y_{i}=$ the variable that we are trying to predict (dependent variable), $x_{i}=$ the variable that we are using to predict $y$ (independent variable), $\alpha=$ the intercept, usually equals to the long-term average of the dependent variable, $\beta_{i}=$ the slope, $\varepsilon=$ the error term or regression residual. $\alpha$ and $\beta$ are also known as regression coefficients.

\section{RESULTS AND DISCUSSIONS}

\section{Rainfall Trend Analyses}

The Sen's slope and Mann-Kendall results of the seasonal and annual trend analysis of accumulated precipitation and the crop yield have been analyzed as per Table 1 .

Table 1: Trend of seasonal rainfall (mm) at Agarfa weather stations from 2001 to 2016

\begin{tabular}{lccccc}
\hline Season & $\begin{array}{l}\text { Mann- } \\
\text { Kendall }\end{array}$ & Sen's Slope & P-value & $\begin{array}{l}\text { Confidence } \\
\text { interval }(\mathrm{CI})\end{array}$ & Linear Trend \\
\hline Winter RF & -14 & -2.4993 & 0.558 & $-14.19-7.7667$ & $244.037-3.297 t$ \\
Spring RF & -24 & -5.8296 & 0.300 & $-15.27-6.5571$ & $352.252-4.056 t$ \\
Summer RF & 18 & 2.9357 & 0.044 & $-6.183-13.59$ & $385.927+4.722 t$ \\
Autumn RF & -6.49 & -2.2417 & 0.082 & $-8.1-9.35$ & $175.487-2.43 t$ \\
Annual RF & -8 & -4.5278 & 0.753 & $-29.98-22.87$ & $1013-1.088 t$ \\
\hline
\end{tabular}

The annual Mann-Kendall test statistic (S) indicated that there was a decreasing rainfall trend for Agarfa farm. This reflects that there was a trend in the time series. Similarly, Sen's slope estimation method proved the existence of a decreasing trend in rainfall by $4.5278 \mathrm{~mm} / \mathrm{year}$ in Agarfa district. Similarly, majority of the farmers during the focus group discussion also acknowledged the decreasing trend in rainfall over the years.

There was a linear decreasing trend of rainfall in Agarfa $\left(y_{t}=1013-1.088 t\right)$. This is to mean that as the value of $t$ increases by one unit the value of annual rainfall decreases by $1.088 \mathrm{~mm}$ (or each year the annual rainfall decreases by $1.088 \mathrm{~mm}$ ). Generally, rainfall trends were variable in Agarfa areas although they were not statistically significant. This variability would ultimately pose a challenge in that crop moisture stress is a definite challenge if cropping operations are not properly timed. The amount of rainfall trends at Agarfa during the growing seasons was significant in the past years (see Table 1).

Monadjem and Perrin [21] reported that rainfall trends are crucial to optimizing the spatial distribution and adaptability of different agricultural enterprises. The high variability in rainfall could mean rain-fed agricultural production remains unpredictable.

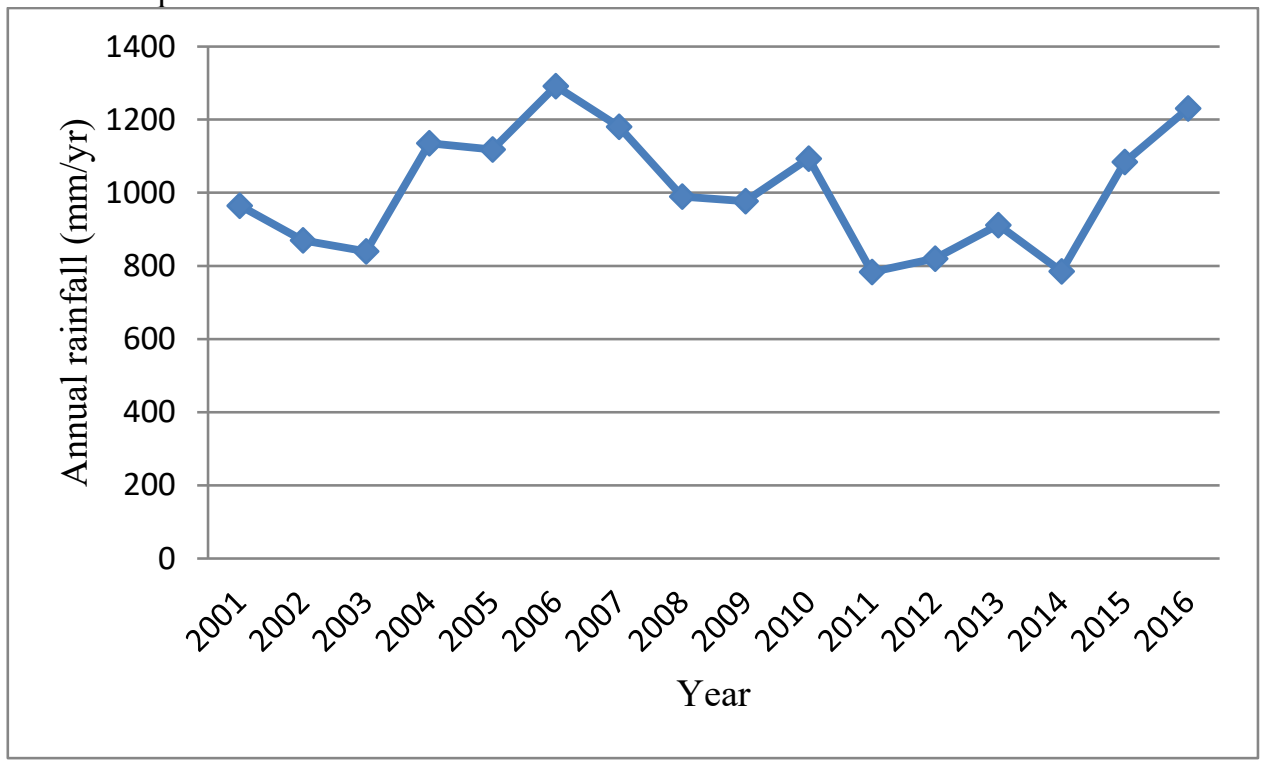

Figure 1: Annual rainfall trend from 2001 to 2016

The annual total rainfall is decreasing over the years; mostly 2011 and 2014 was the anomalous year with a total amount rainfall only $783.3 \mathrm{~mm}$ and $785.1 \mathrm{~mm}$, respectively. The maximum annual amount of rain fall received in 2006 and 2016 accounting for $1291.5 \mathrm{~mm}$ and 1230.7, respectively. In general, Agarfa district receives insufficient total amount of rainfall. The other problem of rainfall distribution was more related to the temporal variability or concentration within a few seasons. In other words, the inconsistency in onset and termination of rainfall should be given a due attention. This trend analysis of rainfall conforms to the work of Alemu [22] who conducted the study in north Wollo of Ethiopia which results in the empirical analysis of rainfall suggested declining rainfall trends. 
Future projection of Rainfall in Ethiopia also depicts that the total rainfall in the coming years shows decreasing trend (See Figure 1). In line with this, the study conducted by Ayalew et al. [23] indicated that by the years 2080s the amount of annual rainfall and number of rainy days will decrease in Ethiopia. Moreover, future projection of rainfall suggests a forward shifting for Kiremt season, and conversely decreases for Belg rainfall in some places of northern Ethiopia [24]. Thus, this indicates that the country's meteorological center with the experts of the climate dynamics should focus on the ways of reducing the risks of decrement in rainfall in the country. Assessing the variability and expected future changes of rainfall is essential for planning and designing appropriate climate change adaptation strategies [25].

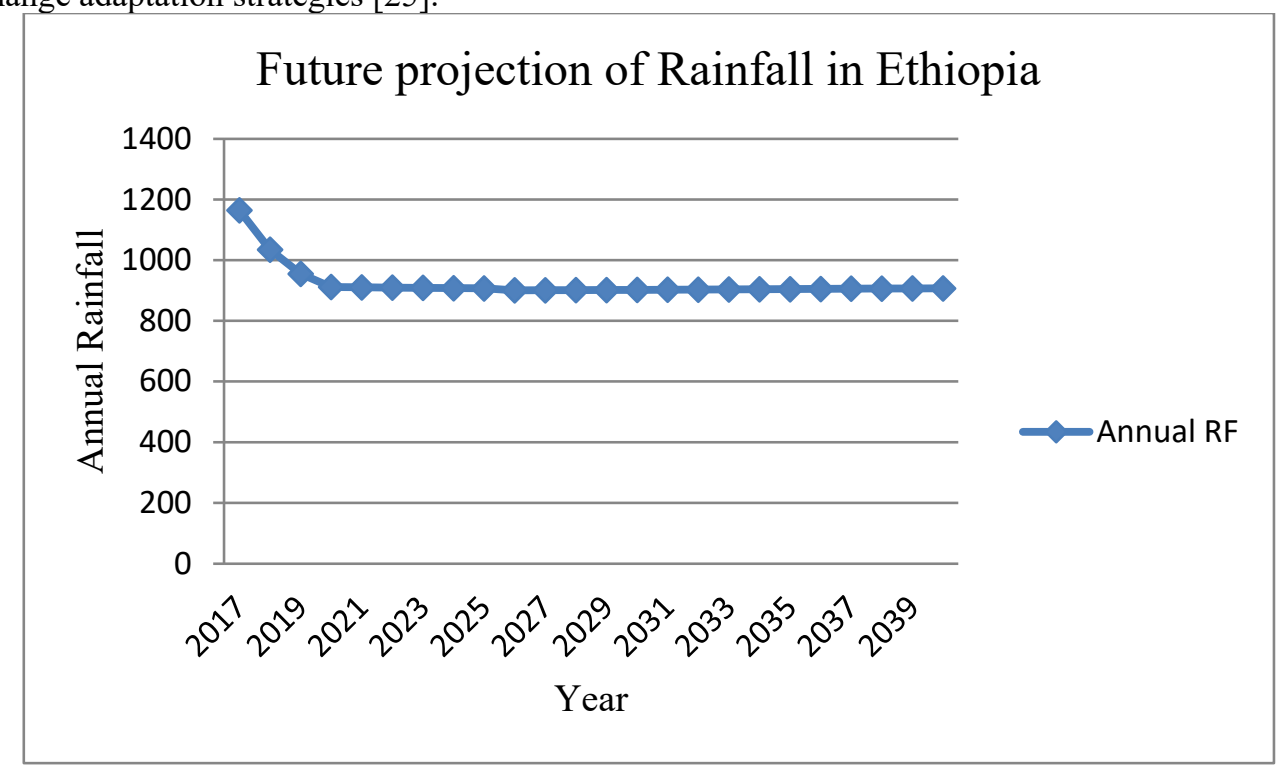

Figure 2: Future projection for Rainfall in Ethiopia

\section{Wheat Production Trend Analysis}

The data for this research implies that, the productivity of winter wheat in the farm over the last 16 years show the trends of ups and downs which victimized by different climatic elements. From Figure 2, it is obvious that the wheat productivity has varied over the past sixteen years (2001-2016) in the Agarfa district. The production in the district mostly oscillated (decreased/increased) sharply over the specified period (2001-2016).

From the graph, production decreased sharply from 2001 to 2003 and thereafter increases sharply to 2004. Again, there was a decrease in production from 2004 to 2005 before rising to 2006 then falling to 2009 then rising to 2010 then falling to 2011 before rising to 2013 the decrement for one then remaining increase for successive two years. It is observed from the time series data that 2006 recorded the highest production of 49 yield/ha. The trend equation and the trend line of the wheat production generally show an increasing trend $\left(y_{t}=26.6121+\right.$ $0.60354 t$ ) which means, even though the increment is statistically insignificant, that the average production over sixteen years (2001-2016) has been increasing.

In the last 16 years crop season, the least productivity was enrolled in 2011 crop season whereas the highest productivity was achieved in 2006 crop season. Generally speaking, the trends of productivity over the last 16 years showed the trends of fluctuation from year to years (see Figure 3 ). 


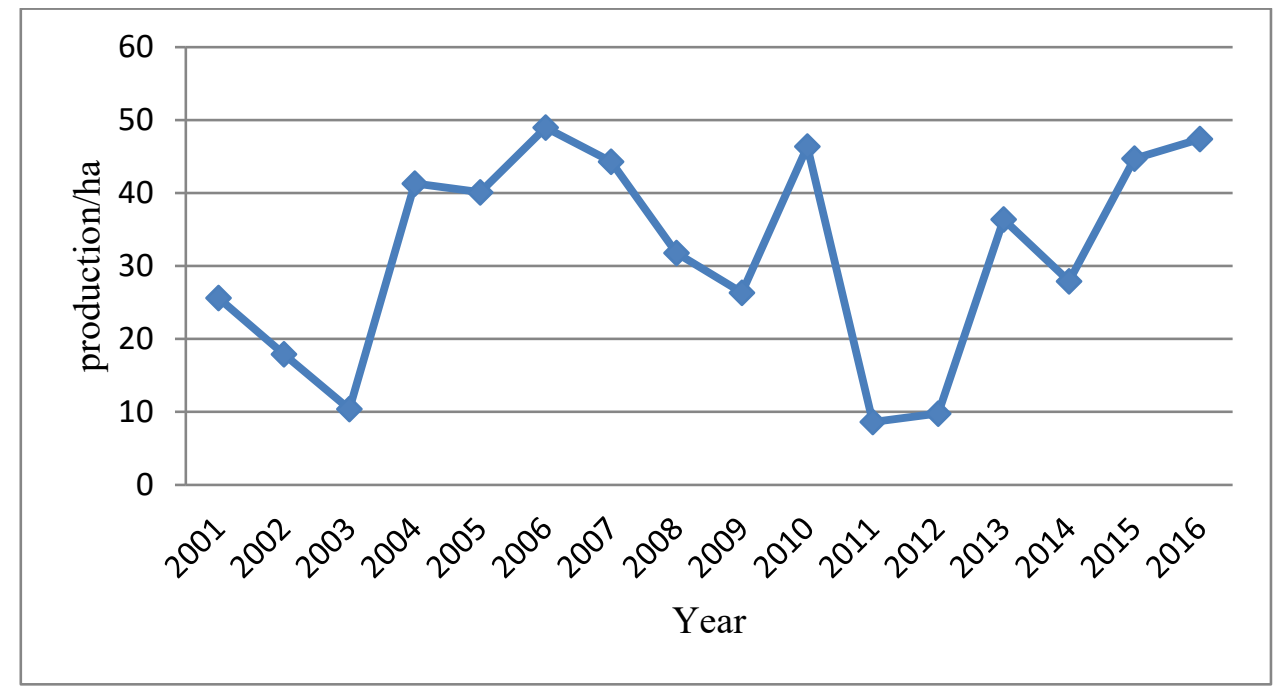

Figure 3: Annual wheat production in Agarfa from 2001 to 2016

Table 2: Trend of wheat production at Agarfa district from 2001 to 2016

\begin{tabular}{lllllc}
\hline Station & $\begin{array}{l}\text { Mann- } \\
\text { Kendall }\end{array}$ & Sen's Slope & P-value & $\begin{array}{l}\text { Confidence } \\
\text { interval (CI) }\end{array}$ & Linear Trend \\
\hline Agarfa & 20 & 0.6779 & 0.39231 & $-1.322-2.599$ & $26.61+0.60354 t$ \\
\hline
\end{tabular}

The Annual Mann-Kendall test statistic (S) indicated that there was an increasing wheat production trend for Agarfa farm. Sen's slope estimation method also proved the existence of an increasing trend in rainfall by 0.6779 yield/ha in Agarfa district.

There was a linear increasing trend of wheat production in Agarfa $\left(y_{t}=26.6121+0.60354 t\right)$. This is to mean that as the value of $t$ increases by one year the value of Production increases by $0.6035 y$ ield/ha. Although crop area, yield and productivity are increasing at a national level, currently, climate change is expected to have significant effects on crop production in the medium to long term period if the present rates of global warming continue unabated [26]. Ethiopia's agriculture is heavily dependent on natural rainfall, with irrigation agriculture accounting for less than $1 \%$ of the total cultivated land. Thus, temperature, the amount and temporal distribution of rainfall and other climatic factors during the growing season are key determinants to the crop yields and, in turn, food shortages, malnutrition and famine [27, 28].

\section{Rainfall and wheat production variability analysis}

Table 3: Drought severity classes of Agarfa district for the last 16 years

\begin{tabular}{|c|c|c|c|}
\hline Year & Total annual rainfall & Standardized Anomaly Index (SAI) & Drought severity classes \\
\hline 2001 & 964.7 & -0.246 & moderate drought \\
\hline 2002 & 869.8 & -0.83 & no drought \\
\hline 2003 & 839.82 & -1.014 & moderate drought \\
\hline 2004 & 1135.42 & 0.804 & no drought \\
\hline 2005 & 1118.4 & 0.699 & no drought \\
\hline 2006 & 1291.5 & 1.764 & no drought \\
\hline 2007 & 1180.8 & 1.083 & no drought \\
\hline 2008 & 989.65 & -0.093 & no drought \\
\hline 2009 & 977.1 & -0.17 & no drought \\
\hline 2010 & 1093.5 & 0.546 & no drought \\
\hline 2011 & 783.3 & -1.362 & severe drought \\
\hline 2012 & 820.1 & -1.136 & moderate drought \\
\hline 2013 & 911.8 & -0.572 & no drought \\
\hline 2014 & 785.1 & -1.351 & severe drought \\
\hline 2015 & 1084.3 & 0.49 & no drought \\
\hline 2016 & 1230.7 & 1.39 & no drought \\
\hline
\end{tabular}


Table 4: The calculation of precipitation concentration index

\begin{tabular}{lccc}
\hline Months & $\begin{array}{l}\text { Long-term mean monthly RF } \\
\text { in mm (Pi) }\end{array}$ & $\begin{array}{l}\text { Rainfall coefficient } \\
\text { (pluviometric coefficient) }\end{array}$ \\
\hline January & 14.00063 & 196.0175 & 0.1672134 \\
February & 72.8325 & 5304.573 & 0.8698587 \\
March & 129.1825 & 16688.12 & 1.542862 \\
April & 114.6375 & 13141.76 & 1.369147 \\
May & 73.95625 & 5469.527 & 0.8832799 \\
June & 136.2375 & 18560.66 & 1.627122 \\
July & 166.3375 & 27668.16 & 1.986615 \\
August & 123.4894 & 15249.63 & 1.474868 \\
September & 97.26875 & 9461.21 & 1.161708 \\
October & 32.0625 & 1028.004 & 0.3829313 \\
November & 25.49375 & 649.9313 & 0.3044789 \\
December & 19.25063 & 370.5866 & 0.2299156 \\
\hline Total & 1004.749 & 113788.2 & \\
\hline
\end{tabular}

$$
P C I=\frac{113788.2}{(1004.749)^{2}} \times 100=11.2715
$$

As shown on the table 4, the precipitation concentration index (PCI) value of Agarfa district is about 11.2715. Thus, Agarfa district precipitation concentration index (PCI) implies the existence of high rainfall concentration.

More precisely, Monkhouse and Wilkinson [29], using pluviometric coefficient signifies values between 0.6 and 1 show low concentration, values 1 to 2 indicate medium concentration while values 2 to 3 show high concentration and the value greater than 3 represents very high concentration of attribute. Pluviometric coefficient calculates any month at a given weather station the ratio of the monthly normal precipitation to one-twelfth of the annual normal precipitation. Thus, the months of December, January, February, October and November have very small concentration of rainfall (dry) while February and May has small amount of rainfall. On the other hand, March, April, June, July, August and September have medium concentration of rainfall.

Again, CV can be computed as: $\mathrm{CV}=\frac{51.92774}{83.72912} \times 100=62.02 \%$. Thus, since the value of coefficient of variation is $62.02 \%$ which is greater than $30 \%$, the rainfall distribution of Agarfa district is highly variable.

On the other hand, standard deviation is computed as the square root of variance and $S D=51.93$ which indicates that the rainfall has less stability.

The Pearson's correlation coefficient is $(r)=0.885$ which indicates there is a very strong positive relationship between the productivity of wheat and annual rainfall. That is, the more shortage a rainfall has, the lower is in productivity of wheat. Squaring the value, we obtain $r^{2}=0.7832$ which is to mean that about $78.32 \%$ of variability in wheat yield accounted for by the variability in amount of annual rainfall.

\section{Implementation of Regression Based Models}

Once the regression model is fitted to the observed values of the wheat production, a thorough examination of the extent to which the fitted model provides an appropriate description of the observed data is a vital aspect of modeling process. R-Square indicates how useful the explanatory variable (annual rainfall) is in predicting the response variable (wheat yield). Hence, Table 7 shows that $R^{2}$ estimates $(0.784)$ indicate that approximately $78.4 \%$ of the variation in the dependent variable (wheat production) can be predicted from the linear combination of the covariate variable (annual rainfall).

\begin{tabular}{lccc}
\multicolumn{5}{c}{ Table 5: Model Summary } \\
$\mathrm{R}$ & $R^{2}$ & Adj. $R^{2}$ & Se \\
0.885 & 0.784 & 0.769 & 6.818
\end{tabular}

The ANOVA technique is used primarily for the specification of interaction terms in linear regressions. The overall goodness of the model can be checked by ANOVA approach. From the following ANOVA table what we simply conclude is that the overall test of the model is significant, because as we can see from Table 6 the P-value (Sig. $=0.000)$ is less than the level of significance $(\alpha$-value $=0.05)$. This is the indication of the goodness of the overall model. Simply it can be said that the model fit the data well.

Table 6: ANOVA

\begin{tabular}{lrrrrr}
\hline Variation & SS & df & MS & F & Sig. \\
Regression & 2362.2 & 1 & 2362.2 & 50.81 & .000 \\
Residual & 650.89 & 14 & 46.49 & & \\
Total & 3013.1 & 15 & & & \\
\hline
\end{tabular}


Simple linear regression is one of the inferential statistical models that relate one response variable with one explanatory variable. From Table 7 , the fitted model will be

$$
\hat{y}=-45.81011+0.07719 x
$$

Where y represents the annual wheat production and $\mathrm{x}$ represents the annual rainfall amount in the Agarfa district.

\begin{tabular}{lrrrr}
\multicolumn{5}{c}{ Table 7: Coefficients } \\
\hline & $\boldsymbol{\beta}$ & Se & t & Sig. \\
Const. & -45.81 & 11.01 & -4.16 & .001 \\
AnnRF & 0.08 & 0.01 & 7.13 & .000 \\
\hline
\end{tabular}

From this model one can understand that the wheat production and amount of rainfall has positive relationship which indicates that as the amount of rainfall increases by one unit the amount of wheat yield increases by 0.08 and vice versa. Again, since the $\mathrm{t}$-value $=7.128$ is large and the corresponding $p$-value $=0.000$ is smaller than $\alpha$ value $=0.05$, the annual rainfall is the major/significant determinants of wheat yield in the specified area.

\section{Coping Strategies of Farmers of the District}

From Table 8 one can see that, the respondents adopted as an option to adopt rainfall variability and its effect at farm and community level using chemicals or irrigation schemes (71.09\%), adjust in cropping calendar, changes in crops variety, crop \& seed selection $(86.72 \%)$, government support program $(25.39 \%)$, diversify household income source $(64.45 \%)$ and community based actions (irrigation, group saving, awareness/information, seed system, crop improvement, etc.) (39.84\%).

Table 8 also depicts that most of the respondents practiced use of crop diversity-growing multiple varieties in the farm $(30.08 \%)$. This strategy seeks to avoid risks of total crop failure rather than maximizing yields of one particular crop [30]. Also in Ethiopia crop diversification is widespread. Crop diversification is the most commonly used method to overcome the impact of climate change and variability in Ethiopia [31]. Diversification is identified as a coping strategy that has evolved to deal with both expected rainfall uncertainty and seasonal fluctuations in rainfall [32]. The others adopted change in seeding and harvesting time and practices $(21.09 \%)$, using crop varieties that tolerate climate stresses $(12.89 \%)$, crop substitutions - change from one species to another $(10.94 \%)$, changes (modification) in seed selection/seed system (10.16\%), participatory crop improvement (7.81\%), use of water management practices/irrigation (4.69\%), and change in crop cultivars $(2.34 \%)$ were among adaptive managements, respectively.

Although farming methods in Ethiopia are still rather traditional, farmers in many areas do have the option of using new, higher-yielding crop varieties [33]. Traditional and contemporary coping mechanisms to climate variability and extremes in Ethiopia include changes in cropping and planting practices [34]. Temesgen et al. [35] research in the Nile Basin of Ethiopia identified that, one of the adaptations amongst farmers was the use of different crop varieties. Rain fed agriculture in sub Saharan Africa will remain vital for food security [32]. At the same time, even though in the study area the usage was very poor, irrigation can be a valuable strategy for making agriculture more stable and safe. Types of irrigation are for example dams and ponds, hand dug wells and other types of wells, flood irrigation, sprinkler irrigation, lifting water using a petrol-fuelled pump engine, and irrigation by gravity $[36,37]$. Use of irrigation is one of the least practiced adaptation strategies among the major adaptation methods identified in Ethiopia [35]. 
Table 8: Assessment of coping mechanism and barriers

\begin{tabular}{|c|c|c|c|}
\hline Issues & Responses & Frequency & Percent \\
\hline \multirow{10}{*}{$\begin{array}{l}\text { The practices that the } \\
\text { farmers have adopted as } \\
\text { option to adopt rainfall } \\
\text { variability at farm and } \\
\text { community level }\end{array}$} & \multirow{2}{*}{$\begin{array}{l}\text { Technology use (use of chemicals, irrigation } \\
\text { schemes etc.) }\end{array}$} & 74 & 28.91 \\
\hline & & 182 & 71.09 \\
\hline & \multirow{2}{*}{$\begin{array}{l}\text { Practices for on farm adaptive management (adjust } \\
\text { in cropping calendar, changes in crops and variety, } \\
\text { crop and seed selection) }\end{array}$} & 34 & 13.28 \\
\hline & & 222 & 86.72 \\
\hline & \multirow{4}{*}{$\begin{array}{l}\text { Policy (government support program, information, } \\
\text { insurance) } \\
\text { Diversity household income source }\end{array}$} & 191 & 74.61 \\
\hline & & 65 & 25.39 \\
\hline & & 91 & 35.55 \\
\hline & & 165 & 64.45 \\
\hline & \multirow{2}{*}{$\begin{array}{l}\text { Community based actions (irrigation, group saving, } \\
\text { awareness, check dams, information, participatory } \\
\text { crop improvement, seed system etc.) }\end{array}$} & 154 & 60.16 \\
\hline & & 102 & 39.84 \\
\hline \multirow{8}{*}{$\begin{array}{l}\text { Among adaptive } \\
\text { management, the } \\
\text { practices for wheat that } \\
\text { the farmers have } \\
\text { practiced in farm }\end{array}$} & $\begin{array}{l}\text { Change in seeding, transplanting and harvesting time and } \\
\text { practices }\end{array}$ & 54 & 21.09 \\
\hline & Change in crop cultivars & 6 & 2.34 \\
\hline & Crop substitutions -change from one species to another & 28 & 10.94 \\
\hline & $\begin{array}{l}\text { Uses of crop diversity-growing multiple varieties in the } \\
\text { farm }\end{array}$ & 77 & 30.08 \\
\hline & using crop varieties/tolerate climate stresses & 33 & 12.89 \\
\hline & & 12 & 4.69 \\
\hline & \multirow{2}{*}{ changes/modification in seed selection/seed system } & 2 & 10.16 \\
\hline & & 20 & 7.81 \\
\hline
\end{tabular}

\section{CONCLUSION AND RECOMMENDATION}

\section{Conclusion}

This study is an attempt to establish the trend of rainfall change and variability and assess the impact of rainfall change on wheat production which may in-turn affects farmer's adaptation.

The Annual Mann-Kendall test statistic (S) indicated that there was a decreasing rainfall trend in Agarfa district. This reflects that there was a trend in the time series data. Similarly, Sen's slope estimation method depicts the existence of a decreasing trend in rainfall by $4.5278 \mathrm{~mm}$ per year in the district. This variability would ultimately pose a challenge in that crop moisture stress is a definite challenge if cropping operations are not properly timed. The amount of rainfall trends at Agarfa during the growing seasons was significant in the past years. The high variability in rainfall could mean rain-fed agricultural production remains unpredictable. The other problem of rainfall distribution was more related to the temporal variability or concentration within a few seasons.

The data for this research implies that, the productivity of winter wheat in the farm over the last sixteen years show the trends of ups and downs which victimized by different climatic elements. As a result of variability in climatic elements, it is observed that the wheat productivity has varied over the past sixteen years in the specified area. The production in the district mostly oscillated (decreased/increased) sharply over the specified period. The trend equation and the trend line of the wheat production generally show an increasing trend which means, even though the increment is statistically insignificant, the average production over sixteen years has been increasing. As a general, the trends of productivity over the last sixteen years showed the trends of oscillations year to year.

The precipitation concentration index value $(\mathrm{PCI}=11.27)$ implies the existence of high rainfall concentration which results in variable rainfall trends. Pluviometric coefficient value indicated that the months of December, January, February, October and November had very small concentration of rainfall (dry) while February and May had small amount of rainfall whereas March, April, June, July, August and September had medium concentration of rainfall. On the other hand, Coefficient of Variation (CV) value $62.02 \%$ implies the rainfall distribution of Agarfa district was highly variable. Similarly, standard deviation $(\mathrm{SD}=51.93)$ of the rainfall indicates that the rainfall had less stability.

On the other hand, the value of $r$ indicated a very strong positive relationship between the productivity of wheat and annual rainfall. That is, the more shortage a rainfall has, the lower is in productivity of wheat i.e. $78.4 \%$ of variation in wheat production accounted for by the amount of annual rainfall variability in the district. The regression model also depicts similar situation. It improved that wheat production and amount of rainfall had positive relationship which indicates that as the amount of rainfall increases by one unit, the amount of production increases by 0.08 and vice versa. In addition, since the $t$-value $=7.128$ is large and the corresponding $p$-value $=0.000$ is smaller than $\alpha$-value $=0.05$, the annual rainfall was the major/significant determinants of wheat production in the specified area.

The respondents adopted as an option to adopt rainfall variability and its effect at farm and community level 
using chemicals or irrigation schemes, adjust in cropping calendar, changes in crops variety, crop \& seed selection, government support program, diversify household income source and community based actions (irrigation, group saving, awareness/information, seed system, crop improvement, etc.) even-though the degree of the usage of these mechanisms were different. Diversification is identified as a coping strategy that has evolved to deal with both expected rainfall uncertainty and seasonal fluctuations in rainfall. The others adopted change in seeding, transplanting and harvesting time and practices, using crop varieties that tolerate climate stresses, crop substitutions -change from one species to another, changes/modification in seed selection/seed system, participatory crop improvement, and use of water management practices/irrigation among adaptive managements, respectively.

Although farming methods in Ethiopia are still rather traditional, farmers in Agarfa, to some extent, do have the option of using new, higher-yielding crop varieties. At the same time, even though the usage was very poor in the study area, irrigation is a valuable strategy for making agriculture more stable and safe. Use of irrigation is one of the least practiced adaptation strategies among the major adaptation methods identified in Agarfa district.

\section{Recommendations}

Based on the findings and conclusions of the study, the researcher forwarded following points as a recommendation to policy makers and planers:

1. As per the result of this study, rainfall is the major determinant of wheat production. Hence, the district's agricultural center and any concerned body should give prior attention to minimize the risks of rainfall variability by using different mechanisms like reforestation, making local meteorology station at nearby, developing coping strategies of farmers.

2. Farmers should be aware about the situations which lead to decrement in rainfall distribution especially due to man-made activities.

3. Even-though the trend of wheat production shows slight increment from the past to recent, the increment is not significant. So the households should try their best to increase the productivity by consulting their local agricultural center in order to increase their adaptive capacity, improve knowledge and skills through training, supported financially (credit) to increase their involvement in small scale irrigation and water harvesting, and to use improved agricultural inputs which can resist the rainfall variability.

4. Formulating effective and efficient planned and anticipatory adaptation strategy, which is depend on indigenous practices of the community. A proper assessment of locally available adaptation options and coping strategies should be considered in order to minimize the effects of rainfall variability.

5. In general, diversification of economic activities can help minimize the risks of climatic disasters. Diversification of agricultural product and moving to more modern and high value crops is an important way of reducing vulnerability of climate dependent rain fed agriculture that have to be suggested for farmers.

\section{References}

1. Lepetz, V. Massot, M. and Schmeller, D.S., and Clobert, J., Biodiversity monitoring: some proposals to adequately study species' responses to climate change. Biodiversity and Conservation, 2009, 18, 3185-3203.

2. IPCC. Climate Change: Impacts, Adaptation, and Vulnerability. Part A: Global and Sectoral Aspects in Contribution of Working Group II to the Fifth Assessment Report of the Intergovernmental Panel on Climate, 2014.

3. Purkey DR, Joyce B, Vicuna S, et al. Robust analysis of future climate change impacts on water for agriculture and other sectors: a case study in the Sacramento Valley. Climate Change, 2008, 87:109-122.

4. Beweket, W., Rainfall variability and crop production in Ethiopia Case study in the Amhara region. Department of Geography and Environmental Studies, Addis Ababa University, 2009.

5. A.M. Fowler and K.J Hennessy, Potential Impacts of Global Warming on the Frequency and Magnitude of Heavy Precipitation Natural Hazards, 1995, 11: 283-303.

6. Matouš P, Mojo, D., Roles of extension and ethno-religious networks in acceptance of resource-conserving agriculture among Ethiopian farmers. Int. J. Agric. Sustain, 2013, 11:301-316.

7. Gebreegziabher Z., Mekonnen A., and Seyoum A., Carbon Markets and Mitigation strategies for Africa/Ethiopia: Literature Review and the way forward: EDRI research report, 2012, 14.

8. World Bank, Ethiopia Over view. http:// www.world bank.org/en/country/ Ethiopia / overview. Accessed 27, June 2013.

9. Bessie, S., Input Supply and Output Marketing Role of Multipurpose Cooperatives in Increasing Cereal Production in Bale Zone (Oromia Regional State), Ethiopia, MSc thesis, Addis-Ababa University, 2010.

10. Bekele F., Demonstrating rainfall variability in barley and wheat production in Bale Zone (south eastern Ethiopia). Ethiopia, MSc thesis, Haramaya University, 2015.

11. Allyn and Bacon, Elementary statistics in social research, New York, Harper and Rowearo and International Maize and Wheat Improvement Center. 1-42. American Statistical Association, 2010, 39:1379-1389. 
12. Yenigun, K., Gumus, V. and Bulut, H., Trends in stream flow of the Euphrates basin, Turkey. Proclamation Institute of Civil Engineering Water Management, 2008, 161:189-198.

13. Karpouzos, D.k., Kavalieratou, S. and Babajimopoulos, C., Trend analysis of Precipitation data in Pieria Region (Greece). European Water, 2010, 30:31-40.

14. Sen, P.K., Estimates of the regression coefficient based on Kendall's tau. J. Am. Stat. Assoc. 1968, 63, 13791389.

15. Conway, A., The science of climate change in Africa: impacts and adaptation. Grantham Institute for Climate Change Discussion paper, 2009, No 1, Pp 24.

16. Hayes, Michael J.; Svoboda, Mark D.; and Wilhite, Donald A., "Monitoring Drought Using the Standardized Precipitation Index". Drought Mitigation Center Faculty Publications. 2000, 70.

17. Ayalew, D., Tesfaye, K., Mamo, G.., Yitaferu, B. and Bayu, W., Variability of rainfall and its current trend in Amhara Region, Ethiopia. African Journal of Agricultural Research, 2012, 7(10):1475-1486.

18. Oliver JE. Monthly rainfall distribution: a comparative index. Prof. Geogr, 2009, 32:300-309.

19. Hare, F.K., Climate and Desertification. Revised analysis (WMO-UNDP) WCP-44, 2001, pp5-20. Geneva, Switzerland.

20. Reddy S. J., Methodology: Agro-climatic Analogue Technique and Applications as relevant to Dry land Agriculture. Agro-climatological Series 8th 86/021-WMO/UNDP/NMSA, Addis Ababa, Ethiopia, 2004, P60.

21. Monadjem and Perrin, Influence of sugarcane plantations on the population dynamics and community structure of small mammals in a savanna-agricultural landscape, 2003.

22. Alemu Eshetu, Impacts of Climate Variability and Change on Food Security and Farmers' Adaptation Strategies in Gubalafto Woreda, North Wollo, Ethiopia, 2016.

23. Ayalew, D., Tesfaye, K., Mamo, G.., Yitaferu, B. and Bayu, W., Variability of rainfall and its current trend in Amhara Region, Ethiopia. African Journal of Agricultural Research, 2012, 7(10):1475-1486.

24. Hadgu, G. Tesfaye K., Mamo G., and Kassa B., Trend and variability of rainfall in Tigray, Northern Ethiopia: Analysis of meteorological data and farmers perception. Academically Journal Environmental Science, 2014, 1(8): 159-171.

25. Thornton, P.K., Jones, P.G., Alagarswamy, A. and Andresen, J., Spatial variation of crop yield responses to climate change in East Africa. Global Environmental Change, 2009, 19:54-65.

26. Ethiopian panel on Climate Change (EPCC)., First Assessment Report, Working Group I Physical Science Basis, Published by the Ethiopian Academy of Sciences, 2015.

27. MoFED., Ethiopia's Agricultural Sector Policy and Investment Framework (PIF), Addis Ababa, Ethiopia, 2007.

28. Mahlet G., Impacts of climate change on the future dynamics of Central African forests, 2013.

29. Monkhouse, F.J., and Wilkinson, H.R., Maps and Diagrams, London, Methuen, 3rd edition, 1971, p522.

30. United Nations Environment Programme (UNEP). Africa's Lakes: Atlas of Our Changing Environment. Nairobi, Kenya, 2006.

31. Bryan E., Temesgen Tadesse, Gbetibono A. and Ringler C. Adaptation to climate, 2009.

32. Cooper, P.J.M., Dimes, J., Rao, K.P.C., Shapiro, B., Shiferaw, B. and Twomlow, S., Coping better with current climatic variability in the rain-fed farming systems of sub-Saharan Africa: An essential first step in adapting to future climate change? Agriculture, Ecosystems and Environment, 2008, 126: 24-35.

33. Weir and Knight, Adoption and Diffusion of Agricultural Innovations in Ethiopia: The Role of Education, 2000 .

34. T. Abebe, Changing Livelihoods, Changing Childhoods: Patterns of Children's Work in Rural Southern Ethiopia, 2007.

35. Temesgen D., Rashid H., Claudia R., Tekie A., Determinants of farmers' choice of adaptation methods to climate change in the Nile Basin of Ethiopia, 2009.

36. CIA, World Factbook, Africa; Ethiopia, URL: https:/www.cia.gov/library/publications/the-worldfactbook/maps/maptemplate et.html (last accessed 01.05.2011).

37. Joto Africa., Adapting to Climate Change in Africa, URL: http://www.eldis.org/id21 ext/publications/JA/JotoAfrikaIssue1.pdf (accessed 16.09.2010) 